\title{
Cap-and-trade properties under different hybrid
}

\section{scheme designs}

\author{
Georg Grüll and Luca Taschini
}

September 2010

Centre for Climate Change Economics and Policy

Working Paper No. 35

Grantham Research Institute on Climate Change and the Environment

Working Paper No. 26 
The Centre for Climate Change Economics and Policy (CCCEP) was established by the University of Leeds and the London School of Economics and Political Science in 2008 to advance public and private action on climate change through innovative, rigorous research. The Centre is funded by the UK Economic and Social Research Council and has five inter-linked research programmes:

1. Developing climate science and economics

2. Climate change governance for a new global deal

3. Adaptation to climate change and human development

4. Governments, markets and climate change mitigation

5. The Munich Re Programme - Evaluating the economics of climate risks and opportunities in the insurance sector

More information about the Centre for Climate Change Economics and Policy can be found at: http://www.cccep.ac.uk.

The Grantham Research Institute on Climate Change and the Environment was established by the London School of Economics and Political Science in 2008 to bring together international expertise on economics, finance, geography, the environment, international development and political economy to create a worldleading centre for policy-relevant research and training in climate change and the environment. The Institute is funded by the Grantham Foundation for the Protection of the Environment, and has five research programmes:

1. Use of climate science in decision-making

2. Mitigation of climate change (including the roles of carbon markets and lowcarbon technologies)

3. Impacts of, and adaptation to, climate change, and its effects on development

4. Governance of climate change

5. Management of forests and ecosystems

More information about the Grantham Research Institute on Climate Change and the Environment can be found at: http://www.Ise.ac.uk/grantham.

This working paper is intended to stimulate discussion within the research community and among users of research, and its content may have been submitted for publication in academic journals. It has been reviewed by at least one internal referee before publication. The views expressed in this paper represent those of the author(s) and do not necessarily represent those of the host institutions or funders. 


\title{
Cap-and-trade Properties under Different Hybrid Scheme Designs*
}

\author{
Georg Grüll ${ }^{a \dagger} \quad$ Luca Taschini ${ }^{b, c \ddagger}$ \\ ${ }^{a}$ University of Duisburg-Essen \\ ${ }^{b}$ London School of Economics \\ ${ }^{c}$ Massachusetts Institute of Technology
}

August 2010

\begin{abstract}
This paper examines the key design mechanisms of existing and proposed cap-andtrade markets. First, it is shown that the hybrid systems under investigation (price floor using a minimum price guarantee, price collar, allowance reserve, options offered by the regulator, and offset relaxation) can be decomposed into a combination of an ordinary cap-and-trade scheme with European- or American-style call and put options. Then, we quantify and discuss the advantages and disadvantages of the proposed hybrid schemes by investigating whether pre-set objectives (enforcement of permit price bounds and reduction of the compliance costs for relevant companies) can be accomplished while maintaining the original environmental targets. Plain vanilla options are proposed as an alternative that reconciles the otherwise conflicting policy objectives.
\end{abstract}

Keywords: Allowance reserve, Price ceiling, Price collar, Price floor, Offset, Safety valve.

JEL Classifications: H23, Q28, Q54, Q58.

*Part of Grüll's research was supported by the University of Duisburg-Essen. Part of Taschini's research was supported by the Swiss National Science Foundation. The authors would like to thank Federica Buricco, Marc Chesney, Denny A. Ellerman, Samuel Fankhauser, Rüdiger Kiesel, John E. Parsons and two anonymous referees for their helpful discussions and comments. This paper was partly written while Taschini was a Research Visiting Fellow at the MIT Center for Energy and Environmental Policy Research, Cambridge, MA - USA. Taschini gratefully acknowledges financial support from the LSE. The usual disclaimers apply.

$\dagger$ Address: Institute of Energy Trading and Financial Services, University of Duisburg-Essen, Germany. E-mail: georg.gruell@uni-due.de

${ }^{\ddagger}$ Corresponding author. Address: The Grantham Research Institute on Climate Change and the Environment, London School of Economics and Political Science, UK. E-mail: 1.taschini1@lse.ac.uk. Research Visiting Fellow, MIT Joint Program on the Science and Policy of Global Change, Cambridge, MA - USA. 


\section{Introduction}

Behind the global interest in marketable permits for air pollution is the recognition that any meaningful climate change policy has to put a price on carbon dioxide emissions. ${ }^{1}$ As explained in Baumol and Oates (1988), pricing greenhouse gas emissions is a fundamental lesson from environmental economics and the theory of externalities. Environmental economists consider that the absence of a price charge for scarce environmental resources such as clean air leads to air pollution. They prescribe, therefore, the introduction of surrogate prices in the form of unit taxes or marketable emission permits in order to induce people to economize in the use of these resources. ${ }^{2}$

Probably because markets for permits are easier to implement politically, carbon markets are currently quite popular among policy makers around the world. In 2005, the European Emissions Trading Scheme (EU ETS) was launched. It is the world's largest carbon market to date, covering more than $40 \%$ of the carbon dioxide emitted in Europe. European member states agreed in December 2008 to extend this scheme until 2020 and open it up to new sectors, most notably aviation. In January 2009, the official launch of the Regional Greenhouse Gas Initiative (RGGI) signed by 10 north-eastern US States, ushered in the carbon market era in North America. A plan to introduce a US-wide cap-and-trade scheme has recently been proposed by the U.S. Congress. Canada demonstrated its interest in linking up with the US scheme, abandoning its own plans for developing an efficiency-based system. In the Pacific area, Australia's Carbon Pollution Reduction Scheme (CPRS) and New Zealand's Emissions Trading Scheme (NZ ETS) are in different stages of development. Finally, Japan is currently considering different options for the development of a market for emission permits. Most of these schemes, however, differ in the way they address common objectives. For instance, several existing and proposed regional trading schemes are surrounded by concerns about the range of acceptable prices for emission permits. Policy regulators, therefore, have suggested the introduction of specific mechanisms to keep the permit price from rising too high or falling too low. The aim of this paper is to investigate currently proposed hybrid schemes in an equilibrium framework for the market of permits. We assess the ability of these schemes to achieve pre-set objectives (enforcement of permit price bounds and reduction of compliance costs for regulated companies) and, at

\footnotetext{
${ }^{1}$ Stern (2007) provides a comprehensive discussion on the economics of climate change.

${ }^{2}$ Under textbook assumptions, marketable emission permits are essentially equivalent to taxes. However, in real world situations with market power, imperfect information, and transaction costs, there are important differences between permits and taxes. We refer to Taschini (2009) for an introductory review of factors that impinge on the effectiveness of marketable permits schemes and to references therein for in-depth proofs of specific differences.
} 
the same time, maintain their original environmental targets.

Few stochastic models describing the equilibrium price dynamics of emission permits are currently available in the literature. Carmona et al. (2009) show in a general setting that the price of emission permits equals the discounted penalty multiplied by the probability of the event of excess demand (i.e. the aggregated cumulative emissions exceed total amount of permits). The models of Seifert et al. (2008), Chesney and Taschini (2008) and Grüll and Kiesel (2009) specify the cumulative emissions process in the framework of Carmona et al. (2009). In the first paper the emission rate of the representative agent follows an arithmetic Brownian motion, while in the other papers firms' emission rate follows a geometric Brownian motion. This implies the total amount of pollution is described by the integral over an arithmetic and a geometric Brownian motion, respectively. The approaches of Chesney and Taschini (2008) and Grüll and Kiesel (2009) differ in the way such an integral is approximated. In particular, Carmona et al. (2009) analyze the effect of windfall profits, Chesney and Taschini (2008) investigate the effect of asymmetric information on the permit price and Grüll and Kiesel (2009) provide a sound theoretical discussion about the permit price slump in 2006 in the EU ETS. These models realistically depict the dynamic price formation of emission permits, accounting for the most important features of the cap-and-trade scheme implemented under the EU ETS. Introducing a stylized version of the equilibrium price formula of emission permits of Carmona et al. (2009) and then extending it, we first investigate the design mechanisms of the most relevant existing and proposed schemes by evaluating their apparent objectives. Second, after Keeler's (1991) results highlighting that the success of pollution control strategies reliant on market permits deeply depends on the enforcement structure, we systematically compare the expected compliance costs of each hybrid scheme to the expected compliance costs of an ordinary scheme. The expected compliance costs are defined as the sum of abatement costs and the costs of allowance purchases for regulated companies. We therefore distinguish between private compliance costs (those of agents being regulated) and any broader concept of social costs. In this paper we attempt to quantify the former. Finally, we assess the impact of each scheme on the original environmental targets.

The present paper is organized as follows. In Section 2 we introduce a stylized version of the stochastic equilibrium price of Carmona et al. (2009). Then, we derive the price properties of emission permits under five different alternatives of scheme designs (price floor using a minimum price guarantee, price collar, allowance reserve, options offered 
by the regulator, and offset relaxation). We determine how each hybrid system affects the equilibrium permit price and whether pre-set objectives (enforcement of permit price bounds and reduction of potential compliance costs for relevant companies) are realistically enforced. Also, we assess the potential impacts on the original environmental targets of the scheme. Finally, we quantify, where possible, the financial burden of the hybrid systems for the regulator and compare it to a standard cap-and-trade system. By decomposing the permit price into two components (the expected compliance value plus the expected implied banking value), Section 3 extends the model to $n$ periods where banking, borrowing, and the obligation to surrender missing permits (hereafter withdrawal) apply. Section 4 concludes and summarizes in three tables the rationale behind each hybrid system, its advantages and disadvantages, and the description of its mechanisms.

\section{Current and Proposed Scheme Design Mechanisms}

In this section we concentrate on the most relevant scheme alternatives proposed by policy regulators to keep the permit price from rising or falling to an inordinate degree. Among suggested mechanisms, introducing a guaranteed price to ensure a minimum price level, setting a price ceiling and price floor (so-called price collar), creating a permit reserve to be deployed when permit prices are too high, and relaxing the maximum amount of offsets valid for compliance (so-called offset relaxation) are the most popular hybrid systems. A hybrid system is generally considered as a tailored combination of price (tax) and quantity (permit) instruments. The idea of creating a hybrid system by combining these two policy tools was first introduced by the seminal papers of Weitzman (1974) and Roberts and Spence (1976). ${ }^{3}$ In any cap-and-trade scheme, there will be always a penalty for non-compliance. If payment of the penalty is an alternative to compliance, as in the framework of Section 2a, the penalty is effectively a price ceiling in a hybrid scheme as discussed by Jacoby and Ellerman (2004). In contrast, if payment of the penalty does not amount to compliance and the company is still obliged to comply as soon as possible, then the scheme contains specific withdrawal provisions. In the following subsections we consistently compare cap-and-trade schemes supplied with a specific mechanism (hereafter hybrid systems) to the cap-and-trade system described in Section 2a (hereafter ordinary system). Our analysis is initially performed in the one-period framework of Carmona et al. (2009) where banking and borrowing are not allowed. Banking and borrowing options have

\footnotetext{
${ }^{3}$ We refer to Hepburn (2006) for a recent overview on the possible combination of price and quantity instruments.
} 
been proposed by environmental economists with the aim of enforcing the credibility of cap-and-trade schemes and allowing a greater flexibility over time. Past literature on the analysis of how banking and borrowing mechanisms affect the price formation of emission permits is extensive. We refer to Rubin (1996) and Schennach (2000) for an analysis of the consequences of banking and borrowing on the inter-temporal trading of emission permits. In Section 3 we extend the model to $n$ periods where banking, borrowing, and withdrawal apply. We first prove that the permit price can be decomposed into two major components: the expected compliance value plus the expected implied banking value. Using such a decomposition, we show that the mathematics and argumentation developed in the sub-sections below apply for any cap-and-trade system defined within some period of time with banking, borrowing, and withdrawal provisions.

By distinguishing the mechanisms under investigation with respect to the use of external offsets for controlling the permit price in the market, we classify the hybrid systems under study into two main groups. The first group of scheme mechanisms relies on the ability of each policy regulator to purchase or sell an (un)limited amount of emission permits. Neglecting possible interdependence with any offset market for the ease of exposure, we investigate these systems from Section $2 \mathrm{~b}$ to Section 2e. Conversely, the second group encompasses those cap-and-trade schemes that recognize offsets as valid credits for compliance purposes. In particular, we study a mechanism where the maximum amount of the offsets that can be used for compliance is a function of the permit price observed on the market. The higher the permit price, the larger the maximum amount of offsets that can be employed for compliance purposes. The remaining hybrid system under study belongs to this group.

\section{2a Ordinary cap-and-trade scheme}

Allowing for stochastic production and abatement costs, revenues from selling produced goods and emission quantities, Carmona et al. (2009) derived the theoretical futures price of permits in the EU ETS framework, where the total pollution net of abatement reductions (the so-called aggregated cumulative emissions) in $[0, t]$ is measured by the stochastic and endogenous process $q_{[0, t]}$. Let us define $P$ as the penalty that has to be paid for each emission unit that is not covered by a permit at the compliance date $T .{ }^{4}$ Also, $N$ is the

\footnotetext{
${ }^{4}$ In Section 3 we show that the penalty $P$ is not the sole determinant of the permit price that is valid for compliance in the current period. The permit price also depends on the expected price of the permit in the future periods. Therefore, it implicitly depends on the future abatement alternatives and their costs
} 
total amount of permits allocated by the policy regulator to relevant companies, i.e. the cap. Both $P$ and $N$ are known values. We can then express a stylized version of the Carmona et al. (2009) equilibrium price formula at time $t$ in terms of the demand $\left(q_{[0, t]}\right)$ and supply $(N)$ of permits, and the enforcement level $(P)$ in monetary units:

$$
F(t, T)=P \cdot \mathbb{P}\left(q_{[0, T]}>N \mid \mathcal{F}_{t}\right)
$$

where, after abatement reductions, $\mathbb{P}\left(q_{[0, T]}>N \mid \mathcal{F}_{t}\right)$ measures the conditional probability of the final total amount of emissions exceeding the initial amount of permits. In other words, it is the probability of the event of a shortage of permits given the set of information available up to time $t$, i.e. $\mathcal{F}_{t}$. Equation (1) shows the existing relationship between the permit price and the aggregated cumulative emissions $q_{[0, T]}$. In particular, this process depends on the penalty level, the available abatement alternatives and their costs. Therefore, $q_{[0, T]}$ is endogenous and it measures emissions and abatement. If permit prices are high (low), then abatement increases (decreases), the probability of the economy being short permits decreases (increases) and, consequently, the permit price decreases (increases). It is worth noting that all relevant information concerning the market price are then conveyed by $q_{[0, T]}$.

In the following sub-sections, we refer to the permit price in the ordinary system by $F(t, T)$, as given in Equation (1). The specific variables needed to describe each hybrid system will be introduced separately in every subsection.

\section{2b Price Floor using a minimum price guarantee}

Apart from the usual presence of banking and borrowing options policy makers have been discussing the introduction of additional mechanisms to reinforce economic incentives at the basis of market-based instruments. In particular, policy makers have been concerned about permit prices that are either too low or too high. The most obvious provision to limit such price variations is to set a price floor or ceiling. This type of mechanism will be investigated in the next section. Instead of a direct intervention on the permit price path, some economists envisage the possibility of eliminating the unfortunate consequences of extremely low permit prices by a proper combination of price (subsidy or other forms of compensation) and quantity (permit) instruments. Roberts and Spence (1976), for instance, propose to remunerate virtuous companies, i.e. companies able to massively reduce in the following regulated periods. 
their pollution emission below their permits allocation, by means of a subsidy.

Similar to situations involving an ordinary system, a company with a permit shortage at compliance date faces a penalty $P$. On the contrary, when a company ends up with an excess of permits, it receives a minimum price guarantee $S$ per unit of permit. This system is very close to the subsidy program envisioned by Roberts and Spence (1976). Let $0<S \leq P$ and let $N$ be the initial amount of permits allocated to relevant companies. We first prove that the permit price is indeed bounded by $S$ from below. We show that the introduction of a minimum price guarantee in fact creates a price floor equal to the guaranteed price. In particular, the futures permit price denoted by $\tilde{F}(t, T)$ in this hybrid system stays in the interval $[S, P]$ :

$$
\begin{aligned}
\tilde{F}(t, T) & =P \cdot \mathbb{P}\left(q_{[0, T]}>N \mid \mathcal{F}_{t}\right)+S \cdot \mathbb{P}\left(q_{[0, T]} \leq N \mid \mathcal{F}_{t}\right) \\
& =P \cdot \mathbb{P}\left(q_{[0, T]}>N \mid \mathcal{F}_{t}\right)+S \cdot\left(1-\mathbb{P}\left(q_{[0, T]}>N \mid \mathcal{F}_{t}\right)\right) \\
& =S+(P-S) \cdot \mathbb{P}\left(q_{[0, T]}>N \mid \mathcal{F}_{t}\right)=S+\frac{P-S}{P} \cdot P \cdot \mathbb{P}\left(q_{[0, T]}>N \mid \mathcal{F}_{t}\right) \\
& =S+\frac{P-S}{P} \cdot F(t, T)=F(t, T)+S\left(1-\frac{F(t, T)}{P}\right),
\end{aligned}
$$

where $F(t, T)=P \cdot \mathbb{P}\left(q_{[0, T]}>N \mid \mathcal{F}_{t}\right)$ is the futures permit price in an ordinary system. The guaranteed price $S$, ensured by the policy regulator at the end of the compliance period, plays effectively the role of a price-floor. More interestingly, we can disentangle this hybrid scheme, emerging with an ordinary system and a European-style put option with strike price $S .^{5}$

We now quantify the impact of this hybrid system on the private compliance cost of regulated companies. Here compliance costs are defined as the sum of abatement costs and the costs of allowance purchases. ${ }^{6}$ Let us define $f_{q}$ as the probability density function of the stochastic process $q_{[0, T]}$ involving emissions and abatement in the entire regulated period.

\footnotetext{
${ }^{5}$ These calculations are an alternative derivation for pricing European call and put options written on emission permits with maturity corresponding to the end of the compliance period. We refer to Chesney and Taschini (2008) for the derivation of a closed-form pricing formula for European-style options on emission permits.

${ }^{6}$ In this paper we assume that the costs incurred by rational agents would not be greater than the expected penalty costs. Thus, setting risk aversion and reputational effects aside, Equation (2) can be seen as a proxy for the cost of compliance, that is, abatement costs plus allowance purchase costs. We thank an anonymous referee for a clarification about the compliance cost definition.
} 
In an ordinary system this expected compliance cost is described by:

$$
E C C=P \int_{N}^{\infty}(x-N) f_{q}(x) d x \geq 0
$$

where $x$ is the final total amount of non-offset emissions. Similarly, the expected compliance costs for regulated companies in this hybrid system are:

$$
E C C^{P F}=P \int_{N}^{\infty}(x-N) f_{q}(x) d x-S \int_{0}^{N}(N-x) f_{q}(x) d x
$$

Because $S \leq P$, a lower bound for $E C C^{P F}$ is given by $P\left(\mathbb{E}\left[q_{[0, T]}\right]-N\right)$. Indeed,

$$
E C C^{P F} \geq P \int_{N}^{\infty}(x-N) f_{q}(x) d x-P \int_{0}^{N}(N-x) f_{q}(x) d x=P\left(\mathbb{E}\left[q_{[0, T]}\right]-N\right) .
$$

Considering Equations (2) and (3), the total expected private compliance costs for regulated companies under this hybrid system are lower than under an ordinary system. In particular, the difference between these costs is:

$$
E C C-E C C^{P F}=S \int_{0}^{N}(N-x) f_{q}(x) d x \geq 0 .
$$

A minimum price guarantee is relatively easy to implement. By limiting the permit price from below, it lowers the expected compliance costs for regulated companies. On the one hand, the presence of a minimum price guarantee provides an effective price floor that reduces the price volatility at the expenses of some variation in the quantity of outstanding permits. This aspect will be discussed in more details in the next section. On the other hand, it could induce a higher stimulus in technology and abatement investments, favoring the achievement of emission reduction targets. Also, the implementation of such a hybrid system might result in a significant financial burden for the environmental policy regulator. The magnitude of this burden is hardly quantifiable a priori.

\section{2c Price collar}

In addition to the previous mechanism, policy makers have discussed the introduction of a fixed price-range (the so-called price collar) within which the permit price can fluctuate. ${ }^{7}$ This mechanism has long been discussed and was recently endorsed by some economists in

\footnotetext{
${ }^{7}$ It should be noted that a price collar can be implemented also by means of a proper combination of price (tax) and quantity (permit) instruments - see Roberts and Spence (1976).
} 
their recommendations for a US cap-and-trade program. ${ }^{8}$ According to policy makers, such a hybrid scheme can reduce the price risk faced by innovating firms, possibly promoting higher investments in abatement technologies. A second rationale behind the introduction of a price collar is the belief that the presence of a minimum (floor) and a maximum (ceiling) price of permits would lower the volatility of the permit price, potentially providing a higher level of price predictability.

We now investigate the implications of a price collar on the pattern of the permit price and on the trading strategies of regulated companies. Let $P$ be again the penalty fee; $p^{\max }$ the price ceiling, i.e. the price at which the policy regulator sells an unlimited amount of permits; and $p^{\text {min }}$ the price floor, i.e. the price at which the policy regulator buys an unlimited amount of permits. The implementation of the price floor as a reserve price in permit auctions is discussed separately at the end of this section. Such a price collar can be broken down into a combination of an ordinary cap-and-trade system and a sum of free-of-charge American-style call and put options. In fact, when the permit price moves above a pre-specified $p^{\text {max }}$ level, regulated companies can (have the right to) purchase at $p^{\max }$ as many permits as they need. This optionality can be quantified by summing up the values of all exercised American call options with strike price $p^{\text {max }}$. Similarly, when the permit price moves below a pre-specified $p^{\text {min }}$ level, regulated companies can (have the right to) sell at $p^{\text {min }}$ their extra permits. This optionality can be quantified by summing up the values of all exercised American put options with strike price $p^{\text {min }}$. However, since the amount of options on offer is unlimited, it is difficult for a policy regulator to foresee the quantity of permits needed to inject into or withdraw from the market. ${ }^{9}$ In other words, it is hard to quantify the amount of exercised American options a priori.

By breaking this hybrid system down into an ordinary system plus free-of-charge American options maturing at compliance time, we attempt to show how complex the task to control the permit price and keep it respectively below $p^{\max }$ or above $p^{\text {min }}$ might be. Let $N_{t-}$ and $N_{t}$ be, respectively, the amount of outstanding permits before $(t-)$ and after $(t)$ the intervention of the policy regulator on the market for permits. Let $\alpha_{t}=N_{t}-N_{t-}$ denote the amount of permits added $\left(\alpha_{t}>0\right)$ or subtracted $\left(\alpha_{t}<0\right)$ to the market at time $t$. At

\footnotetext{
${ }^{8} \mathrm{~A}$ cap-and-trade system constrains the quantity of emissions, whereas the costs of control are left uncertain. Maniloff and Murray (2009) and PEW (2009) suggest in two distinct memos some policy options (safety valves, price collars, or related mechanisms) that can be implemented in order to address price concerns.

${ }^{9}$ Actually, the total number of American put options cannot exceed the number of allowances initially issued by the policy regulator.
} 
each instant of time $t=0, \ldots, T$ we can identify three possible situations:

1. If the permit price is between the price collar, $F(t, T) \in\left(p^{\min }, p^{\max }\right)$, then $\alpha_{t}=0$ and there is no market intervention by the regulator on the amount of outstanding permits, i.e. $N_{t}=N_{t-}$.

2. If the permit price exceeds $p^{\max }$, the policy regulator is then ready to supply an unlimited amount of additional permits. This means that regulated companies that buy permits at the price ceiling are in fact exercising American call options with a strike price $p^{\max }$. Therefore, relying on standard arbitrage arguments, the theoretical amount of permits $\alpha_{t}>0$ (corresponding to the exercised amount of American call options) that drives the market price of permits back to $p^{\max }$ is:

$$
P \cdot \mathbb{P}\left(q_{[0, T]}>N_{t-}+\alpha_{t} \mid \mathcal{F}_{t}\right)=p^{\max }
$$

The rationale behind this equality is based on a standard supply-demand mechanism: a larger supply of permits increases the downside pressure on the permit market price. However, as described below, the extra (unknown) amount $\alpha_{t}$ causes an unpredictable change in the level of the cap generating extra uncertainty about the quantity of outstanding emission permits.

3. If the permit price drops below $p^{\text {min }}$, the policy regulator is then ready to buy an unlimited amount of permits at the price floor. This means that regulated companies that sell permits at the price floor are exercising American put options with strike price $p^{\text {min }}$. Similarly to the previous case, and relying on the same arbitrage arguments, the theoretical amount of permits $\alpha_{t}<0$ (corresponding to the exercised amount of American put options) that drives the market price of permits up to $p^{\text {min }}$ is:

$$
P \cdot \mathbb{P}\left(q_{[0, T]}>N_{t-}+\alpha_{t} \mid \mathcal{F}_{t}\right)=p^{\text {min }}
$$

The supply-demand mechanism is exactly the same, but works in the opposite direction.

The basic rationale behind market-based instruments is that the market sets a price for scarce resources. So, all relevant information about emissions, abatement alternative and their costs, and penalty should be priced in Equation (1). Based on this concept, Grüll and Kiesel (2009) justify the permit price slump in 2006 in the EU ETS market that followed 
the publication of the verified emission data by the European Commission. ${ }^{10}$ As described above, when the permit price falls outside the price collar, the policy regulator intervenes in the permit market. In particular, the (unknown) amount $\alpha_{t}$ affects the outstanding number of emission permits. and creates uncertainty about the level of the cap. Blending in with expectations on emissions and abatement, the extra stochastic factor $\alpha_{t}$ enhances uncertainty on the supply side. The market intervention affects the trading strategies of regulated companies as described in the next paragraphs.

Under this scheme call and put options are effectively offered in an unlimited quantity keeping the permit price within the specified price bounds. As explained below, regulated companies will never exercise their American options before maturity. ${ }^{11}$ The rationale behind such a strategy is based on the fact that companies do not physically need the permits to produce and, more importantly, they have to achieve compliance only at one time (typically the end of the regulated period). When $F(t, T)$ is close or equal to $p^{\max }$, an advisable trading strategy for regulated companies that are potential buyers is to wait until the end of the regulated period on the hope that $F(t, T)<p^{\max }$. As in the case of an American call option written on a financial underlying that pays no dividends, it is never optimal to exercise American call before maturity. Similarly, when the permit price is close or equal to $p^{\text {min }}$, it would be rational for potential sellers to wait until the end of the regulated period on the hope that $F(t, T)>p^{\text {min }}$ in the interim.

To better understand this, let us distinguish the permit positions of various firms. When the permit price approaches the price ceiling, those companies that need to acquire allowances for compliance will wait to see if prices are lower in the time remaining to maturity, since they would never end up paying more than the exercise price $p^{\max }$. Thus, as mentioned above, companies short of allowances would never exercise an American call option prior to maturity. However, companies in permit excess would face a situation where they could not expect a higher price and it would seem to be in their interest to sell at such a moment. On the opposite side of the collar, one would not expect companies in permit excess to sell before maturity as the price approached or hit the minimum, since it could only get better. Also, one would expect companies in permit shortage to buy in the market at such times. These incentives would set up a trading dynamics prior to $T$ whereby longs

\footnotetext{
${ }^{10}$ The sudden expectation of a market of permits severely in excess of allowances caused an immediate price adjustment. The price drop was sustained in large part because banking was not allowed in the first phase of the EU ETS. See Section 3 for further discussions on banking and borrowing.

${ }^{11}$ Because regulated companies never exercise their American call options prior to maturity, the penalty level is effectively reduced from $P$ to $p^{\max }$.
} 
sell into the market and shorts back away as $p^{\max }$ is approached. The converse holds as $p^{\text {min }}$ is approached: namely, longs retire from, and shorts enter into, the market. These dynamics prevent a situation in which the permit price can go outside the price collars prior to maturity. ${ }^{12}$ At the same time, these dynamics complicate further the regulator's task in identifying an appropriate $\alpha_{t}$ and, not surprisingly, enhance the overall uncertainty.

The price collar is a hybrid system whose objectives (setting a minimum and a maximum permit price) are often achieved. This system corresponds to an ordinary scheme with American call and put options with strike price $p^{\max }$ and $p^{\min }$, respectively. Intuitively, the expected compliance costs for regulated companies in such a system are lower than in an ordinary one. However, this scheme has major disadvantages too. First, it is hard for a policy regulator to quantify a priori the amount of permits needed to inject into or withdraw from the market to control the permit price. Second, the market interventions of the regulator add uncertainty about the outstanding number of emission permits. Therefore, a price collar trades off price volatility for a more uncertain cap level. Third, the regulator faces a financial burden by offering American put options for free. When an American put option is exercised, the regulator buys back permits (leaving unaffected its original environmental targets) at a price $p^{\text {min }} \cdot{ }^{13}$ However, offering an unlimited number of American call options does not result in a financial burden for the regulator. In fact, when an American call option is exercised, the regulator creates the corresponding permit (loosening its original environmental targets) and sells it for $p^{\max }$. In total, the policy regulator might face severe expenses that are unquantifiable a priori or, conversely, its original environmental targets might be significantly loosened. This last consequence might be difficult to justify to public stakeholders.

The scheme described so far implements the price floor as a continuously-offered subsidy -Section $2 \mathrm{~b}$ implements a one-time subsidy- contingent on the permit price being smaller then $p^{\text {min }}$. In this setup, the price floor is indeed a cost to the policy regulator. When considering a policy that implements the price floor as a reserve price in permit auctions, such a result is reversed. In this case, the policy regulator offers permits for sale if the resulting auction price is higher then $p^{\text {min }}$. However, in such a situation companies are not offered traditional put options. Depending on the submitted bids, participating companies

\footnotetext{
${ }^{12}$ We thank an anonymous referee for further clarifications about this price dynamics.

${ }^{13}$ As the policy regulator can at most buy back the total amount of initial permits, the upper bound of the cost of this hybrid scheme can be trivially quantified as $N \cdot p^{\text {min }}$.
} 
might not be able to purchase permits at the requested price. More importantly, $p^{\min }$ maybe not the minimum observable price. A system that implements a price ceiling as a reserve price in auctions cannot actually guarantee the upper price bound if the demand for the allowances at the upper bound price exceeds the supply, the auction can bid the price higher. Thus, this system can be translated into an ordinary cap-and-trade scheme combined with an unlimited amount of American-style call options with strike price $p_{\max }$.

\section{2d Allowance Reserve}

Another common mechanism proposed by economists to manage the economic (and unpopular) consequences of excessively high permit prices is to set a permit (or allowance) reserve. ${ }^{14}$ This hybrid scheme has again been proposed by Murray et al. (2009). ${ }^{15}$ The allowance reserve is very similar to the mechanism of the price ceiling. The main difference is that the maximum amount of permits available in the market equals $N^{\max }$. In other words, the regulator sets the allowance reserve $\eta$ equal to $N^{\max }-N$, where $N^{\max }>N$. Similar to the price collar, the allowance reserve can be broken down into an ordinary cap-and-trade system and a limited sum of free-of-charge American-style call options. In practice, when the permit price moves above a pre-specified $p^{\max }$ level, regulated companies can (have the right to) purchase permits at $p^{\max }$ up to a limited amount $\eta$. This optionality can be quantified as the value of $\eta$ American call options with strike price $p^{\max }$.

Unlike the price collar, the finite nature of the reserve $\eta$ cannot guarantee the price ceiling once the reserve has been completely deployed. As opposed to the previous hybrid system, the limitation in the available extra amount of permits allows us to quantify the expected compliance costs for regulated companies. In particular, the difference between the expected compliance costs of an ordinary system and the hybrid system with allowance reserve equals:

$$
E C C-E C C^{A R}=\left(P-p^{\max }\right) \int_{N}^{N+\eta}(x-N) f_{q}(x) d x \geq 0
$$

where $P$ is the penalty level and $x$ is the final total amount of non-offset emissions. Letting $P^{c}$ be the price of an American call option with strike price $p^{\max }$, we can quantify a lower

\footnotetext{
${ }^{14}$ Here we consider those situations where the permit reserve is solely employed to control excessively high permit prices.

${ }^{15}$ For a comprehensive discussion of the merits of the allowance reserve, we refer to Murray et al. (2009).
} 
bound for such difference relying on the fact that $P^{c} \leq P-p^{\max }$ :

$$
E C C-E C C^{A R} \geq P^{c} \int_{N}^{N+\eta}(x-N) f_{q}(x) d x
$$

The smaller the price ceiling, the lower the expected compliance costs of this hybrid system. Conversely, and unsurprisingly, $E C C^{A R}=E C C$ when $p^{\max }$ equals the penalty level P. ${ }^{16}$

The major disadvantage of the allowance reserve is its inability to guarantee the price ceiling once the reserve has been completely exploited. Due to the constrained ability of the policy regulator to modify the level of the cap, the allowance reserve is a limited device to control the permit price volatility. Finally, in order to implement this scheme and partially lower the expected costs of emission control for regulated companies, the policy regulator faces new costs. Unlike the price collar, these costs are bounded. Yet, price control is possible at the expense of original environmental targets.

\section{2e Plain-vanilla Options by the Regulator}

The final mechanism under investigation concerns the offering of European- and Americanstyle options at the inception of the compliance period for a certain price. This hybrid scheme has been proposed by Unold and Requate (2001), although they do not specify the type of options under discussion. This mechanism is closely related to the previous mechanisms (the price floor with a subsidy, the price collar and the allowance reserve). Accordingly, all these mechanisms belong to the group of hybrid systems that rely on the ability of the policy regulator to create or withdraw permits. As described in Section $2 b$, a price floor which has been enforced using a subsidy is equivalent to an ordinary cap-andtrade system coupled with European put options. The price collar and the allowance reserve described in Sections 2c and 2d can be broken down into an ordinary system coupled with an unlimited or limited amount of American-style options. By offering standard American and/or European options at the beginning of the compliance period, a policy regulator can replicate the results enforced by a minimum price guarantee, or a price collar, or an allowance reserve reconciling the otherwise conflicting policy objectives. It should be noted, however, that this mechanism limits the price exposure exclusively of those companies that purchase options. More remarkably, this mechanism avoids the undesirable manipulation

\footnotetext{
${ }^{16}$ This corresponds to the case discussed by Jacoby and Ellerman (2004).
} 
of relevant information about the amount of emission permits which is caused by the other hybrid systems. Clearly, as in any standard financial market, an extremely large amount of outstanding options, perhaps concentrated in the hands of few companies, might result again in undesired market price manipulation. Such an event, however unlikely, can be prevented by the policy regulator employing necessary corrective actions, such as screening options buyers.

Under the assumption that the regulator offers the options at a fair market price, the expenses borne by the regulator to implement this scheme are zero, as concluded by Unold and Requate (2001). ${ }^{17}$ The risk of writing options is offset by dynamically adjusting the hedging portfolio (i.e. by buying and selling an appropriate number of allowances). By writing and hedging call options, the regulator does not create extra allowances. Therefore, hedged options do not affect the total number of outstanding permits leaving the original environmental target unaffected. This scheme does not guarantee that the price will fall within a certain range. However, the permit price bounds are guaranteed for those regulated companies that require this protection and are willing to pay for this optionality. Yet, implementing this mechanism does not add uncertainty about the level of the cap or the amount of outstanding permits.

\section{2f Offset relaxation}

The model of Carmona et al. (2009) does not explicitly consider the interdependence between the markets of the emission permits and the emission offsets. In order to incorporate such an interdependence we first define the maximum amount of offsets valid for compliance purposes as $\lambda \cdot N$, where $0<\lambda<1$. Because we want to accommodate for the presence of restriction on the use of offsets for compliance, we restrict the maximum amount of valid credits (permits plus offsets) by two times the initial amount of permits $N$. Now, the stylized permit price becomes:

$$
F(t, T)=P \cdot \mathbb{P}\left(q_{[0, T]}-\min \left\{c_{[0, T]}, \lambda N\right\}>N \mid \mathcal{F}_{t}\right)
$$

\footnotetext{
${ }^{17}$ Unold and Requate (2001) raise the delicate question of whether the state or a private institution should offer these options. We believe that the private sector should not be prevented from selling options. In the unlikely case where options are not offered by the private sector, however, the policy regulator acts as a seller of last resort.
} 
where $c_{[0, T]}$ is the stochastic process that denotes the total amount of offsets available for compliance purposes. Because it might be possible that the maximum amount of valid offsets is greater than the number of offset projects available on the market, we take the minimum between $\lambda N$ and $c_{[0, T]}$. We now derive the theoretical price bounds (lower and upper) for emission permits, in the presence of restrictions on the use of offsets.

\section{Theorem 1 (Bounds for emission permit price)}

Let $\lambda \in[0, \infty)$. Let $c_{[0, T]}$ be a continuous random variable on $[0, C) \subseteq[0, \infty)$. Then

(a) $F(t, T) \in\left[F_{l}(t, T), F_{u}(t, T)\right]$ where

$$
\begin{aligned}
& F_{l}(t, T)=P \cdot \mathbb{P}\left(q_{[0, T]}>(1+\lambda) N \mid \mathcal{F}_{t}\right), \\
& F_{u}(t, T)=P \cdot \mathbb{P}\left(q_{[0, T]}>N \mid \mathcal{F}_{t}\right)
\end{aligned}
$$

(b) $F(t, T)$ is a non-increasing function in $\lambda$ for $\lambda \in\left[0, \frac{C}{N}\right)$ and constant in $\lambda$ for $\lambda \geq \frac{C}{N}$.

Proof :

(a) The lower and upper bound are derived by using

$$
\begin{aligned}
& \min \left\{c_{[0, T]}, \lambda N\right\} \leq \lambda N \\
& \min \left\{c_{[0, T]}, \lambda N\right\} \geq 0
\end{aligned}
$$

(b) Let $c_{[0, T]}$ be a random variable on $[0, C)$. If $\lambda \geq \frac{C}{N}$, then

$$
\min \left\{c_{[0, T]}, \lambda N\right\}=c_{[0, T]}
$$

Thus for $\lambda \geq \frac{C}{N}$ the permit price is equal to: $P \cdot \mathbb{P}\left(q_{[0, T]}-c_{[0, T]}>N \mid \mathcal{F}_{t}\right)$. Let $0<\lambda<\Lambda<$ $\frac{C}{N}$. Then we have that $\min \left\{c_{[0, T]}, \lambda N\right\} \leq \min \left\{c_{[0, T]}, \Lambda N\right\}$ almost surely, which completes the proof.

Several existing and proposed cap-and-trade have provisions about the use of international offsets for compliance purposes. For these schemes, a popular mechanism which aims to keep the price of emission permits from rising too high is the so-called offset relaxation. This mechanism works by relaxing the limitations on the maximum amount of offsets that can be used for compliance purposes. This mechanism is, for instance, implemented in the Regional Greenhouse Gas Initiative (RGGI) in the United States. The RGGI is the first mandatory, market-based scheme in the United States to reduce greenhouse gas emissions. 
As mentioned in Section 1, under the RGGI ten Northeastern and Mid-Atlantic states agreed to cap and reduce their $\mathrm{CO}_{2}$ emissions from the power sector by $10 \%$ by 2018 . The RGGI allows power companies to buy offsets to meet their compliance. ${ }^{18}$ However, the use of these offsets is constrained to 3.3 percent of a power plant's total compliance obligation. The offset relaxation expands this limit to 5 percent and 10 percent if given $\mathrm{CO}_{2}$ permit price thresholds are consecutivley reached in the market. Let us now study this scheme considering the situation where such a mechanism might be extended to an international or global market. Using the price properties shown above, we first derive the theoretical pattern of the price of permits in the presence of this type of offset relaxation. Then, we discuss its effectiveness and quantify the corresponding expected compliance costs for regulated companies.

Assuming that the price of the offsets is solely determined by the level of emission of relevant companies, and using the approach presented above, the permit price is given by:

$$
\bar{F}(t, T)=P \cdot \mathbb{P}\left(q_{[0, T]}-\min \left\{\lambda(t) N, c_{[0, T]}\right\}>N \mid \mathcal{F}_{t}\right)
$$

where $P$ is the penalty level and $N$ denotes the number of allowances handed out by the regulator. Let $\lambda(t)$ be an increasing step function, taking the values $0<\lambda_{0}<\lambda_{1}<$ $\lambda_{2}<\ldots<\lambda_{n}$. As in the RGGI scheme, at each instant $t$ the regulator allows utilities to use $\lambda(t) \cdot N$ offsets for compliance. Let $\left\{\bar{F}_{1}, \ldots, \bar{F}_{n}\right\}$ be the increasing ordered constants corresponding to permit price thresholds set by the policy regulator at the beginning of the scheme. In this framework, $t_{i}=\inf \left\{t, \bar{F}(t, T)=\bar{F}_{i}\right\}$, where $i=1, \ldots, n$ defines the instant when the permit price $\bar{F}(t, T)$ hits the price threshold $\bar{F}_{i}$. Especially, we have that $\lambda\left(t_{i}\right)=\lambda_{i}$. This means that the maximum amount of offsets that can be used for compliance at time $t$ depends on the permit price $\bar{F}(t, T)$ observed on the market at that time. Such a system implies that, as soon as the permit price reaches a pre-specified price barrier $\bar{F}_{i}, \lambda(\cdot)$ jumps from $\lambda_{i-1}$ to $\lambda_{i} \cdot{ }^{19}$ This additional quantity for the maximum amount of offsets valid for compliance results in an immediate increase in the potential supply base of valid credits and, possibly, causes a permit price drop. Looking at the price level around

\footnotetext{
${ }^{18}$ A RGGI offset permit represents a project-based greenhouse gas emission reduction outside the capped electric power generation sector. The RGGI participating states limit the award of offset permits only to five project categories. Furthermore, all offset projects must be located within one of the RGGI participating states.

${ }^{19}$ It is interesting to observe that the EU ETS implements a specific case of this mechanism. There the function $\lambda(t)$ is constant, i.e. $\lambda(t) \equiv \lambda^{E U}$, whereas in the RGGI it is an increasing step function where the step values are $\lambda_{0}=0.033, \lambda_{1}=0.05, \lambda_{2}=0.1$.
} 
each instant $t_{i}$, we can observe that at time $t<t_{i}$ the permit price is:

$$
\bar{F}(t, T)=P \cdot \mathbb{P}\left(q_{[0, T]}-\min \left\{\lambda_{i-1} N, c_{[0, T]}\right\}>N \mid \mathcal{F}_{t}\right)
$$

By definition, at time $t=t_{i}$ the permit price is equal to:

$$
\bar{F}(t, T)=\bar{F}_{i} .
$$

At time $t>t_{i}$, after the offset relaxation has been triggered and the maximum amount of offset that can be used has been increased, the permit price equals:

$$
\bar{F}(t, T)=P \cdot \mathbb{P}\left(q_{[0, T]}-\min \left\{\lambda_{i} N, c_{[0, T]}\right\}>N \mid \mathcal{F}_{t}\right)
$$

Similarly to the proof in Theorem 1, it can be shown that $\bar{F}(t, T)$ is a non-increasing function in $\lambda(t)$. However, the response of the permit price to the increase in $\lambda(\cdot)$ heavily depends on the random variable $q_{[0, T]}$ and the available amount of offset projects that is captured by $c_{[0, T]}$. A larger maximum quota of usable offsets, therefore, does not necessarily lead to a permit price decrease. As such, the effectiveness of employing offsets in terms of capping a permit price increase is rather limited.

We now quantify the expected compliance costs for regulated companies of this hybrid system and compare it with an ordinary system. Let us assume that the maximum amount $\lambda N$ of offsets valid for compliance purposes in the ordinary cap-and-trade system corresponds to $\lambda N \equiv \lambda_{0} N>N$, and $\lambda_{0}<\lambda_{1}<\lambda_{2}<\ldots<\lambda_{n}$. As we have already shown (cf. Theorem 1) that the emission permit price is a non-increasing function in $\lambda$, it is trivial to show that prices of emission permits in a hybrid system with offset relaxation are lower than in an ordinary cap-and-trade system. This statement clearly implies lower expected compliance costs for regulated companies under this scheme.

In sum, an offset relaxation reduces expected compliance costs for regulated companies at no extra cost for the policy regulator. Furthermore, relaxing the restrictions on the use of offsets is relatively easy to implement. Quite remarkably, an offset mechanism leads to a lower price of permits, but a schedule of expanding offset limits at pre-set price levels may not reduce the permit price further than the permit price in the presence of a fixed offset level. Yet, under this alternative there would be no upper limit for the permit price, much like the allowance reserve. The success of this scheme highly depends on the ability of the 
policy regulator to set correct price thresholds $\bar{F}_{i}$. This requires good skills in modeling and forecasting the supply of offsets $\left(c_{[0, T]}\right)$ and the demand of permits $\left(q_{[0, T]}\right)$. Finally, the fact that the maximum amount of offsets useful for compliance purposes is a function of the (stochastic) price of emission permits, is a disadvantage for offsets project developers because it increases the overall uncertainty of the project revenues.

\section{$3 \quad$ Banking with limited borrowing}

So far we have considered a one-period framework in absence of temporal flexibility. This section generalizes our approach when banking, borrowing, and withdrawal apply. In particular, banking allows for the transfer of an unlimited number of unused allowances from the present compliance period into the next. Borrowing allows for the transfer of a limited number of allowances from the next compliance period back into the present one. Withdrawal accounts for the case where the payment of the penalty does not amount to compliance. This requires non-compliant companies to hand in the missing allowances using their allocation for the next compliance period.

Let us consider a finite n-period setup, i.e. after the last period unused permits have no redemption value. Regulated companies have to comply at the end of each compliance period $\{i, i=1, \ldots, n\}$ (hereafter $i$-th period). A company that does not comply at time $T_{i}$ has to pay a penalty $P^{(i)}$ and surrender the missing permit using its allocation for the next compliance period. Regulated companies have the opportunity to bank unused permits into the next period. A company that does not comply at time $T_{n}$ has to pay the penalty $P^{(n)}$. However, all unused allowances have no redemption value after $T_{n}$. Considering this extended setup, the price of the permit in the $i$-th period at time $t \leq T_{i}$ is ${ }^{20}$

$$
F\left(t, T_{i}\right)=\sum_{j=i}^{n} e^{-r\left(T_{j}-T_{i}\right)} P^{(j)} \mathbb{P}\left(\sum_{k=1}^{j} q_{\left[T_{k-1}, T_{k}\right]}>\sum_{k=1}^{j} N^{(k)} \mid \mathcal{F}_{t}\right),
$$

where $r$ is the interest rate; $q_{\left[T_{i-1}, T_{i}\right]}$ measures the total pollution in the $i$-th period net of abatement reductions; and $N^{(i)}$ denotes the allocated permits in the $i$-th period.

Usually, a quantity of interest is the price of the permit in the current compliance period,

\footnotetext{
${ }^{20}$ The proof is in the appendix.
} 
i.e. the 1-period permit price. This quantity corresponds to:

$$
\begin{aligned}
F\left(t, T_{1}\right) & =P^{(1)} \mathbb{P}\left(q_{\left[0, T_{1}\right]}>N^{(1)} \mid \mathcal{F}_{t}\right)+\sum_{j=2}^{n} e^{-r\left(T_{j}-T_{1}\right)} P^{(j)} \mathbb{P}\left(\sum_{k=1}^{j} q_{\left[T_{k-1}, T_{k}\right]}>\sum_{k=1}^{j} N^{(k)} \mid \mathcal{F}_{t}\right) \\
& :=P^{(1)} \mathbb{P}\left(q_{\left[0, T_{1}\right]}>N^{(1)} \mid \mathcal{F}_{t}\right)+B_{t} .
\end{aligned}
$$

This equation shows that the permit price can be decomposed into two components. The first component of Equation (9) is the expected value of compliance in the current period. The second component, $B_{t}$, corresponds to the expected banking and borrowing values implied in the permit price. More precisely, $B_{t}$ can be broken down into several values of banking (borrowing) the permit into (from) one of the consecutive periods. Therefore, $B_{t}$ measures the value of the consecutive opportunities to bank/borrow starting from the current compliance period. This implies that $B_{t}$ can only take non-negative value, i.e. $B_{t} \geq 0$. In a uncertain long-term regulatory framework, forecasting future emissions and abatements of regulated companies is a hard task. Therefore, we can assume $B_{t}$ is a non-negative stochastic process independent from the process $q_{\left[0, T_{1}\right]}$. By using the 1-period permit price, we show below that the presence of banking, borrowing, and withdrawal does not alter the validity of our approach used in Section 2.

\section{Price floor using a minimum price guarantee}

In Section $2 \mathrm{~b}$ we show that the introduction of a minimum price guarantee creates a price floor equal to the subsidy $S$. Moreover, the permit price can be regarded as the price of the permit in an ordinary scheme plus the value of a European put option with strike price $S$. In a framework where banking and limited borrowing apply, this result still holds. Recalling Equation (9), the proof requires the technical assumption that $B_{t}$ is a martingale taking values in $[0, S]$. This assumption corresponds to the belief that, at time $t$, the best estimate of the future value of $\left\{B_{s}, t<s \leq T_{n}\right\}$ is $B_{t}$, i.e. the current value. When $P^{(1)}>S>B_{t}$, the 1-period permit price in the hybrid scheme is

$$
\begin{gathered}
\tilde{F}\left(t, T_{1}\right)=P^{(1)} \cdot \mathbb{P}\left(q_{\left[0, T_{1}\right]}>N^{(1)} \mid \mathcal{F}_{t}\right)+B_{t}+\left(S-B_{t}\right) \cdot \mathbb{P}\left(q_{\left[0, T_{1}\right]} \leq N^{(1)} \mid \mathcal{F}_{t}\right) \\
\stackrel{(9)}{=} F\left(t, T_{1}\right)+\left(S-B_{t}\right) \cdot \mathbb{P}\left(q_{\left[0, T_{1}\right]} \leq N^{(1)} \mid \mathcal{F}_{t}\right) .
\end{gathered}
$$

The last equation corresponds to the sum of the permit price in the ordinary scheme plus the value of a European put option written on $F\left(t, T_{1}\right)$ with strike price $S$ and maturity $T_{1}$. This last component is obtained evaluating a put option contract at time $t$ and maturity 
$T_{1}$ :

$$
\begin{array}{rl}
\mathbb{E} & {\left[\left(S-F\left(T_{1}, T_{1}\right)\right)^{+} \mid \mathcal{F}_{t}\right]=\mathbb{E}\left[\left(S-P^{(1)} \cdot \mathbf{1}_{\left\{q_{\left[0, T_{1}\right.}>N^{(1)}\right\}}-B_{T_{1}}\right)^{+} \mid \mathcal{F}_{t}\right]} \\
\stackrel{\text { indep. }}{=} & \int_{0}^{\infty} \mathbb{P}\left(q_{\left[0, T_{1}\right]}>N^{(1)} \mid \mathcal{F}_{t}\right) \cdot\left(S-P^{(1)}-x\right)^{+} f_{B_{T_{1}}}(x) d x \\
& +\int_{0}^{\infty} \mathbb{P}\left(q_{\left[0, T_{1}\right]} \leq N^{(1)} \mid \mathcal{F}_{t}\right) \cdot(S-x)^{+} f_{B_{T_{1}}}(x) d x \\
S<P^{(1)} \& B_{t}>0 & \mathbb{P}\left(q_{\left[0, T_{1}\right]} \leq N^{(1)} \mid \mathcal{F}_{t}\right) \int_{0}^{\infty}(S-x)^{+} f_{B_{T_{1}}}(x) d x \\
\stackrel{S>B_{t}}{=} & \mathbb{P}\left(q_{\left[0, T_{1}\right]} \leq N^{(1)} \mid \mathcal{F}_{t}\right) \int_{0}^{\infty}(S-x) f_{B_{T_{1}}}(x) d x \\
= & \mathbb{P}\left(q_{\left[0, T_{1}\right]} \leq N^{(1)} \mid \mathcal{F}_{t}\right)\left(S-\mathbb{E}\left[B_{T_{1}} \mid \mathcal{F}_{t}\right]\right) \\
\stackrel{\text { mart. }}{=} & \mathbb{P}\left(q_{\left[0, T_{1}\right]} \leq N^{(1)} \mid \mathcal{F}_{t}\right)\left(S-B_{t}\right) .
\end{array}
$$

Therefore, also in the presence of banking and limited borrowing the scheme can be regarded as the sum of the permit price in an ordinary scheme plus the value of a European put option with maturity equal to the compliance date $T_{1}$. When $S<B_{t}$, unused permits would be banked rather than handed in to the regulator in order to receive the guaranteed

price $S$. Again, $\tilde{F}\left(t, T_{1}\right)$ corresponds to the sum of the permit price in the ordinary scheme plus the value of a (out-of-the money, i.e. zero value) European put option.

\section{Price collar and Allowance Reserve}

Under both a price collar and an allowance reserve, the market intervention of the regulator is intended to be a prompt reply to a temporary shock of the permit price outside the set bounds. Therefore, in a $n$-period framework, the level of $\alpha_{t}$ can be realistically considered of a smaller magnitude with respect to the total amount of present and future outstanding allowances. It is reasonable then to assume that the amount of permits injected into or withdrawn from the market does not affect $B_{t}$ significantly. This is an even milder assumption in the presence of a long-term regulatory framework, i.e. when there are several many consecutive compliance periods.

So, the amount of permits $\tilde{\alpha}_{t}$ that prevent the permit price from rising too high (falling too low) in a system where banking and borrowing apply is

$$
P^{(1)} \cdot \mathbb{P}\left(q_{\left[0, T_{1}\right]}>N_{t-}^{(1)}+\tilde{\alpha}_{t} \mid \mathcal{F}_{t}\right)+B_{t}=p^{\max } \quad\left(\text { or } p^{\min }\right),
$$

where $\tilde{\alpha}_{t}>0\left(\tilde{\alpha}_{t}<0\right)$. Therefore, the mathematics and argumentation developed in Sec- 
tion 2c and 2d hold also when banking, borrowing, and withdrawal apply.

\section{Offset relaxation}

Similar to the previous case, under an offset relaxation scheme the increase in the maximum amount of offset valid for compliance can be considered a prompt reply to a temporary price shock. Again, in a $n$-period framework, the increase in the level of $\lambda(\cdot)$ can be realistically considered of a smaller magnitude with respect to the total amount of present and future outstanding allowances. Therefore, Equation (8) becomes

$$
F\left(t, T_{1}\right)=P^{(1)} \cdot \mathbb{P}\left(q_{\left[0, T_{1}\right]}-\min \left\{c_{\left[0, T_{1}\right]}, \lambda N^{(1)}\right\}>N^{(1)} \mid \mathcal{F}_{t}\right)+B_{t}
$$

As in the previous situations, using the decomposition of Equation (9) the argumentation in Section $2 \mathrm{f}$ holds also in a system with offset relaxation when banking, borrowing, and withdrawal apply.

\section{Conclusions}

Using a stylized equilibrium permit price, we analyze five different cap-and-trade schemes characterized by specific price mechanisms. These hybrid systems are implemented by the policy regulators in order to prevent the permit price from rising too high or falling too low. By distinguishing those mechanisms that rely on the ability of the policy regulator to control permit quantity (price floor with a minimum price guarantee, price collar, allowance reserve, standard options) from those that employ offsets, we quantify their impact on the permit price.

An interesting result of this paper is that all the hybrid systems that we have investigated, with the exception of the offset relaxation, can be translated into an ordinary cap-andtrade scheme combined with European-style put options (price floor with a minimum price guarantee); with an unlimited amount of American-style call (price floor as a reserve price in permit auction) and put options (price collar); with a limited amount of Americanstyle call and put options (allowance reserve); with a limited amount of European- and American-style call and put options (standard options offered by the regulator). Employing such a breakdown, we show that price bounds of emission permits can be always guaranteed in a hybrid system with a minimum price guarantee or in a system with price collar. A 
system where the regulator sells options to regulated companies guarantees price bounds for those companies that are willing to pay for such a protection. The other systems under study (price floor as a reserve price in permit auction, allowance reserve and offset relaxation) cannot guarantee that the permit price will be constrained under all possible circumstances. Those hybrid systems that are able to effectively guarantee price bounds reduce price volatility, albeit at the expenses of an unpredictable change in the level of the cap. In particular, the unknown quantity of permits released into or withdrawn from the market adds uncertainty about the outstanding number of emission permits. Decomposing the permit price into two components (the expected compliance value plus the expected implied banking value), we show that these results hold also when banking, borrowing, and withdrawal apply.

Moreover, because the success of cap-and-trade schemes depends significantly on the enforcement structure, we systematically compare the expected compliance costs for regulated companies of each hybrid scheme to the expected compliance costs of an ordinary scheme. We show that all proposed hybrid systems reduce (in expectation) the private economic burden of the cap-and-trade for regulated companies. However, in implementing these schemes the regulator faces substantial costs (price collar), limited costs (price floor, allowance reserve), or no-costs at all (offset relaxation). At the same time, the original environmental targets are severely loosened (price collar), or lowered (allowance reserve and offset relaxation). The hybrid scheme with standard options maintains the environmental targets under control and does not impose extra costs on the policy regulator.

Based on these results, we argue that a cap-and-trade system where plain-vanilla options are available reconciles the otherwise conflicting policy objectives. It first replicates the intentional results of each hybrid system and avoids undesirable effects such as loosening the original environmental target or requiring extra financial efforts from the policy regulator. Second, by purchasing an appropriate combination of options, each regulated company can reproduce the best suitable hybrid scheme. Quite remarkably, companies have the opportunity to make the scheme adaptable to their company-specific abatement alternatives. Therefore, the option approach seems to be the most flexible mechanism among the ones under investigation. The challenge in the coming years will be the creation of properly designed option contracts on emission permits backed by sufficiently liquid option markets. Further studies on the ability of financial options to offer a real hedge against the risk of compliance is in our agenda for future research. 


\section{References}

Baumol, W. J. and Oates, W. E. (1988). The Theory of Environmental Policy. Cambridge University Press, Cambridge.

Carmona, R., Fehr, M., Hinz, J., and Porchet, A. (2009). Market design for emission trading schemes. SIAM Review, 9(3):465-469.

Chesney, M. and Taschini, L. (2008). The endogenous price dynamics of emission allowances and an application to $\mathrm{CO}_{2}$ option pricing. Swiss Banking Institute, University of Zürich, Switzerland.

Grüll, G. and Kiesel, R. (2009). Pricing $\mathrm{CO}_{2}$ permits using approximation approaches. Preprint.

Hepburn, C. (2006). Regulating by prices, quantities or both: an update and an overview. Oxford Review of Economic Policy, 22(2):226-247.

Jacoby, H. D. and Ellerman, A. D. (2004). The safety valve and climate policy. Energy Policy, 32(4):481-491.

Keeler, A. (1991). Non compliant firms in transferable discharge permit market: Some extensions. Journal of Environmental Economics and Management, 21:180-189.

Maniloff, P. and Murray, B. (2009). Discussion Memo on H.R. 2454 American Clean Energy and Security Act. Technical report, Nicholas Institute for Environmental Policy Solutions.

Murray, B. C., Newell, R. G., and Pizer, W. A. (2009). Balancing cost and emissions certainty: An allowance reserve for cap-and-trade. Review of Environmental Economics and Policy, 3(1):84-103.

Musiela, M. and Rutkowski, M. (2002). Martingale Methods in Financial Modelling. Springer-Verlag.

PEW (2009). Climate Policy Memo n. 6: Cost Containment and Offset Use in the American Clean Energy and Security Act (Waxman-Markey). Technical report, Pew Center for Climate Change.

Roberts, M. and Spence, M. (1976). Effluent charges and licenses under uncertainty. Journal of Public Economic, 5(3):193-208. 
Rubin, J. D. (1996). A model of intertemporal emission trading, banking, and borrowing. Journal of Environmental Economics and Management, 31:269-286.

Schennach, S. M. (2000). The economics of pollution permit banking in the context of Title IV of the 1990 Clean Air Act Amendments. Journal of Environmental Economics and Management, 40:189-210.

Seifert, J., Uhrig-Homburg, M., and Wagner, M. (2008). Dynamic behavior of $\mathrm{CO}_{2}$ spot prices. Journal of Environmental Economics and Managements, 56:180-194.

Stern, N. (2007). The Economics of Climate Change. The Stern Review. Cambridge University Press, Cambridge - UK.

Taschini, L. (2009). Environmental economics and modeling marketable permits: A survey. Asian Pacific Financial Markets - forthcoming.

Unold, W. and Requate, T. (2001). Pollution control by options trading. Economics Letters, 73:353-358.

Weitzman, M. L. (1974). Prices vs. quantities. Review of Economic Studies, 41(4):683-691. 


\section{Proof of the decomposition of the permit price when banking and borrowing apply}

Let us consider a finite horizon setup with $n$ periods where banking and limited borrowing apply. Then, the price of the permit in the $i$-th compliance period at time $t \leq T_{i}$ is

$$
F\left(t, T_{i}\right)=\sum_{j=i}^{n} e^{-r\left(T_{j}-T_{i}\right)} P^{(j)} \mathbb{P}\left(\sum_{k=1}^{j} q_{\left[T_{k-1}, T_{k}\right]}>\sum_{k=1}^{j} N^{(k)} \mid \mathcal{F}_{t}\right) .
$$

Proof :

The formula is obtained by backward induction. At time $T_{h}, 1 \leq h \leq n-1$, the price of the allowance in the $h$-th compliance period is given by

$$
\begin{aligned}
F\left(T_{h}, T_{h}\right)= & \underbrace{\mathbb{1}_{\left\{q_{\left[T_{h-1}, T_{h}\right]} \leq N^{(h)}+\beta^{(h)}\right\}} e^{-r\left(T_{h+1}-T_{h}\right)} F\left(T_{h}, T_{h+1}\right)}_{\text {compliance scenario at } T_{h}}+ \\
& \underbrace{\mathbb{1}_{\left\{q_{\left[T_{h-1}, T_{h}\right]}>N^{(h)}+\beta^{(h)}\right\}}\left(P^{(h)}+e^{-r\left(T_{h+1}-T_{h}\right)} F\left(T_{h}, T_{h+1}\right)\right)}_{\text {non-compliance scenario at } T_{h}} \\
& =\mathbb{1}_{\left\{q_{\left[T_{h-1}, T_{h}\right]}>N^{(h)}+\beta^{(h)}\right\}} P^{(h)}+e^{-r\left(T_{h+1}-T_{h}\right)} F\left(T_{h}, T_{h+1}\right),
\end{aligned}
$$

where

$$
\beta^{(h)}=\sum_{k=1}^{h-1}\left(N^{(k)}-q_{\left[T_{k-1}, T_{k}\right]}\right) \quad \text { and } \quad T_{0}=0 .
$$

$\beta^{(h)}$ represents the net amount of permits that have been banked and borrowed throughout all compliance periods up to period $h-1$. A positive (negative) number correspond to net banking (borrowing). Due to the penalty at the end of each compliance period and the withdrawal provision, borrowing will be limited. $\mathbb{1}_{\{\cdot\}}$ is the indicator function that equals 1 when the condition $\{\cdot\}$ is satisfied. Otherwise, it is zero. The first component of Equation (11) represents the case of compliance in period $h$. If this condition holds, unused permits can be banked. So, the permit price valid for compliance in this period must be equal to the permit price valid for compliance in the following periods. Otherwise, intertemporal arbitrage opportunities would exist. The second component of Equation (11) represents the case of non-compliance in the $h$-th compliance period. In this circumstance, the withdrawal provision applies. Equation (12) shows that the permit price in the $h$-th compliance period depends on the penalty $P^{(h)}$ and on the expected price of the permit in the future periods $\{r, r=h+1, \ldots, n\}$. Therefore, it implicitly depends on the future 
abatement alternatives and their costs.

Recalling that $\mathbb{E}\left[\mathbb{1}_{\{\cdot\}}\right]=\mathbb{P}(\{\cdot\})$ and that futures are martingales, i.e. $\mathbb{E}\left[F\left(T_{a}, T_{b}\right) \mid \mathcal{F}_{t}\right]=$ $F\left(t, T_{b}\right)$ for $t \leq T_{a} \leq T_{b}$, the price of the permit in the $h$-th compliance period at time $t \leq T_{h}$ is given by ${ }^{21}$

$$
F\left(t, T_{h}\right)=P^{(h)} \mathbb{P}\left(\sum_{k=1}^{h} q_{\left[T_{k-1}, T_{k}\right]}>\sum_{k=1}^{h} N^{(k)} \mid \mathcal{F}_{t}\right)+e^{-r\left(T_{h+1}-T_{h}\right)} F\left(t, T_{h+1}\right) .
$$

Using that

$$
F\left(t, T_{n}\right)=P^{(n)} \mathbb{P}\left(\sum_{k=1}^{n} q_{\left[T_{k-1}, T_{k}\right]}>\sum_{k=1}^{n} N^{(k)} \mid \mathcal{F}_{t}\right)
$$

completes the proof.

\footnotetext{
${ }^{21}$ It has been shown that the conditional expected value of futures contracts $F\left(T_{a}, T_{b}\right)$ with respect to the information-set up to time $t$, for $t \leq T_{a} \leq T_{b}$, equal $F\left(t, T_{b}\right)$ - see Musiela and Rutkowski (2002).
} 


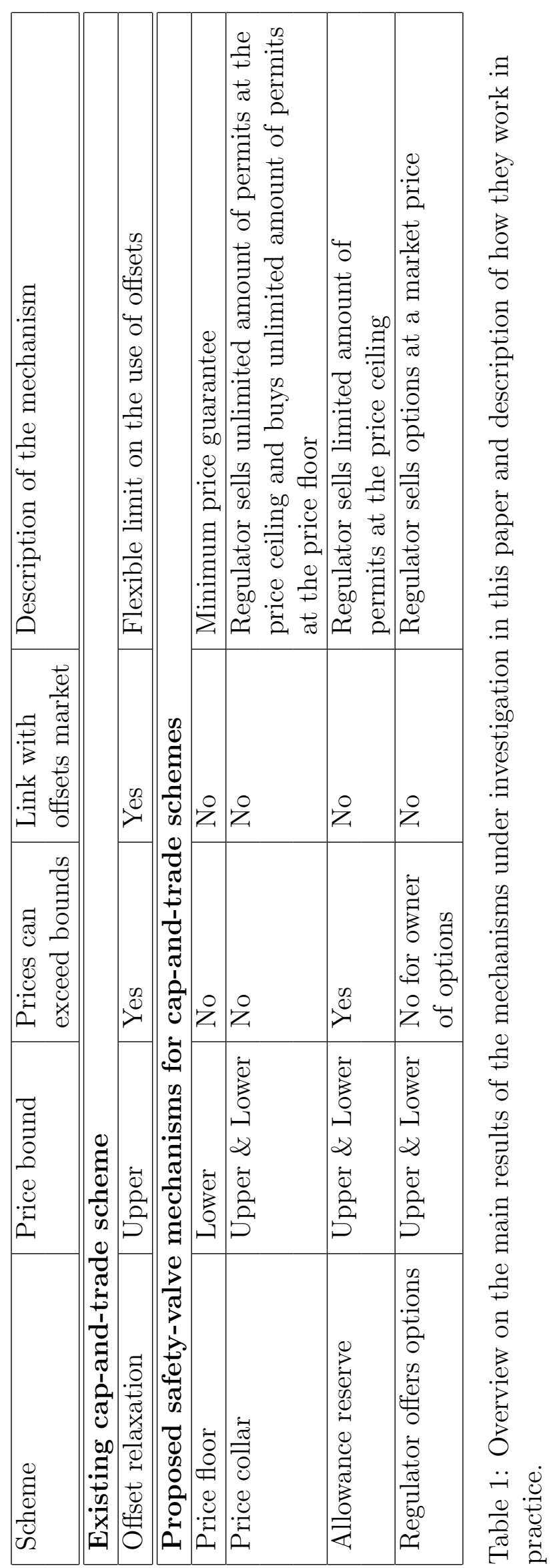




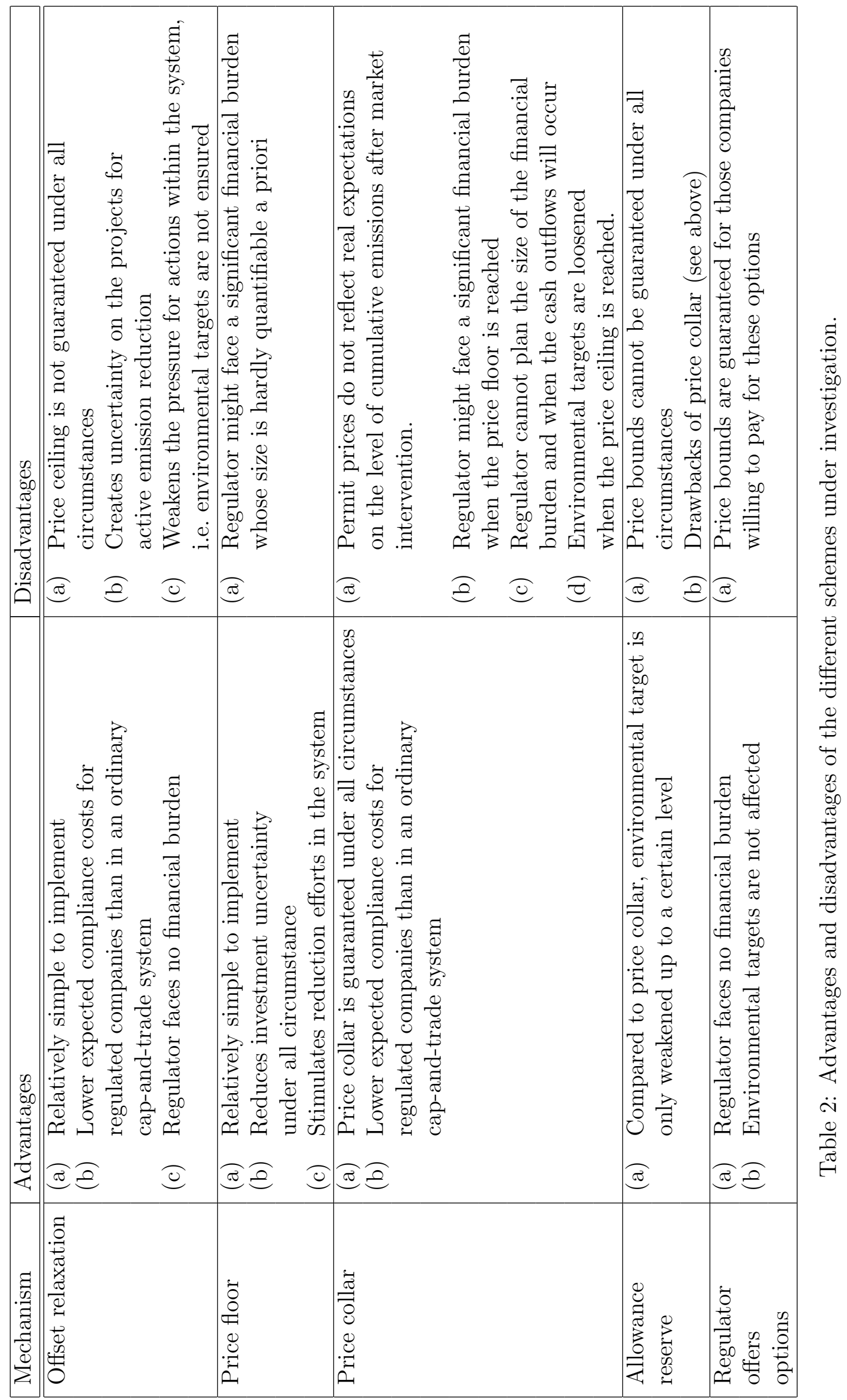




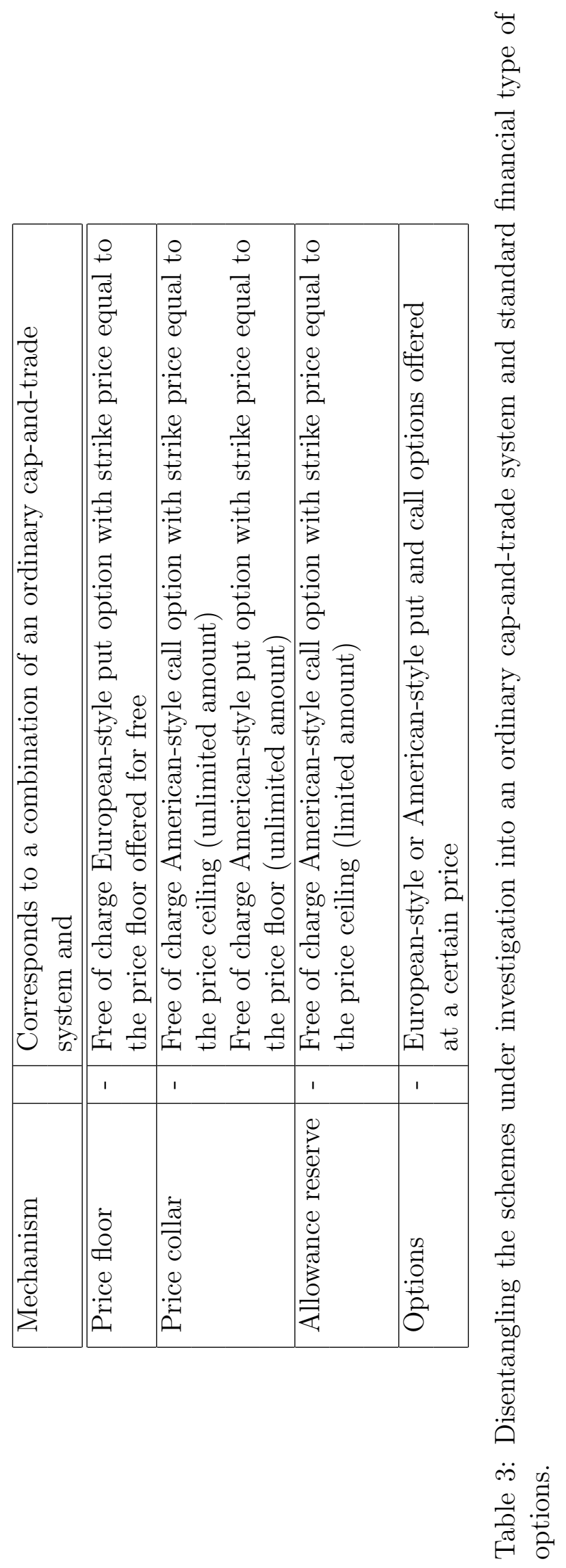

